\title{
Understanding ranger motivation and job satisfaction to improve wildlife protection in Kahuzi-Biega National Park, eastern Democratic Republic of the Congo
}

\author{
Charlotte Spira, Andrew E. Kirkby and Andrew J. Plumptre
}

\begin{abstract}
Rangers in the Democratic Republic of the Congo are working to conserve some of the largest remaining blocks of tropical rainforest, along with iconic species that are being targeted by poachers for subsistence or commercial purposes. During 2015-2016 we surveyed $72 \%$ of Kahuzi-Biega National Park rangers to assess their level of job satisfaction, why they chose to become rangers, what they liked and disliked about their job, and what affected their motivation to conduct their work. We used a cumulative link model to assess how various factors affected their self-reported level of job satisfaction. The rangers surveyed had been working in the Park for 16 years on average and most chose this occupation to earn a salary, to conserve wildlife or to serve their country. Overall, ranger job satisfaction was low; however, our findings highlight numerous ways in which this could be improved. These include higher salaries, more promotion opportunities, better recognition from the Congolese wildlife authority and other state services, positive performance incentives, better security, improved living conditions in remote patrol posts, and more support from the judicial system. Ranger patrol assignment (i.e. type of patrol and Park sector to patrol), receiving free housing at the Park headquarters, age, and length of service were statistically significant predictors of job satisfaction. It is likely that increasing ranger job satisfaction would result in a higher commitment to protecting wildlife, improved performance, and positive outcomes for wildlife conservation.
\end{abstract}

Keywords Cumulative link model, Democratic Republic of the Congo, front-line conservation, job satisfaction, Kahuzi-Biega, law enforcement, motivation, wildlife rangers

\section{Introduction}

Tildlife crime and poaching are of increasing concern, with populations of targeted species declining rapidly and an increasing number of species at risk of extinction (Butchart et al., 2010; Lawson \& Vines, 2014; Plumptre et al., 2016). Significant resources have been allocated to law enforcement efforts to counter ever more organized poaching networks that cause billions of dollars of economic losses to governments (Lawson \& Vines, 2014; Biggs et al., 2015; The World Bank, 2016). Among the people working to counter these threats are wildlife law enforcement rangers, who account for a significant portion of the global conservation workforce.

Assessments of wildlife law enforcement effectiveness have used quantitative measures such as patrol effort, number of seizures, reduction in threats, or species numbers (Leader-Williams et al., 1990; Claridge et al., 2005; Hilborn et al., 2006; Jachmann, 2008; Stokes, 2010; Hötte et al., 2016), but few studies have taken into consideration the human dimension of the rangers themselves (Jachmann, 2008; Moreto et al., 2015; Moreto, 2016). Effective law enforcement requires that officers perform well in their job (Jachmann, 2008). Besides human and financial resources, leadership, management systems, equipment, training, logistics and security, there are a myriad of other factors that may affect the performance of protected area rangers (Henson et al., 2016). In particular, occupational satisfaction and motivation have been found to be positively correlated with job performance (Judge et al., 2001).

Numerous studies, most of which have been conducted in the USA, have investigated job satisfaction among police officers. Commonly studied aspects have included officers' demographics (e.g. age, years of service, level of education), job tasks (e.g. variety, autonomy, stress) and organizational characteristics (e.g. supervisor feedback, organizational support; O'Leary-Kelly \& Griffin, 2013). Age, length of service, contributing to the public good, conducting mindexpanding activities, performance, perceived work autonomy, work engagement, burnout, and supervisor support and feedback have all been found to be related to, or key determinants of, occupational satisfaction among police officers (Hoath et al., 1998; Zhao et al., 1999; Toch 2002; Brough \& Frame, 2004; Rothmann, 2008; Miller et al., 2009; Johnson, 2012; Lambert et al., 2015). 


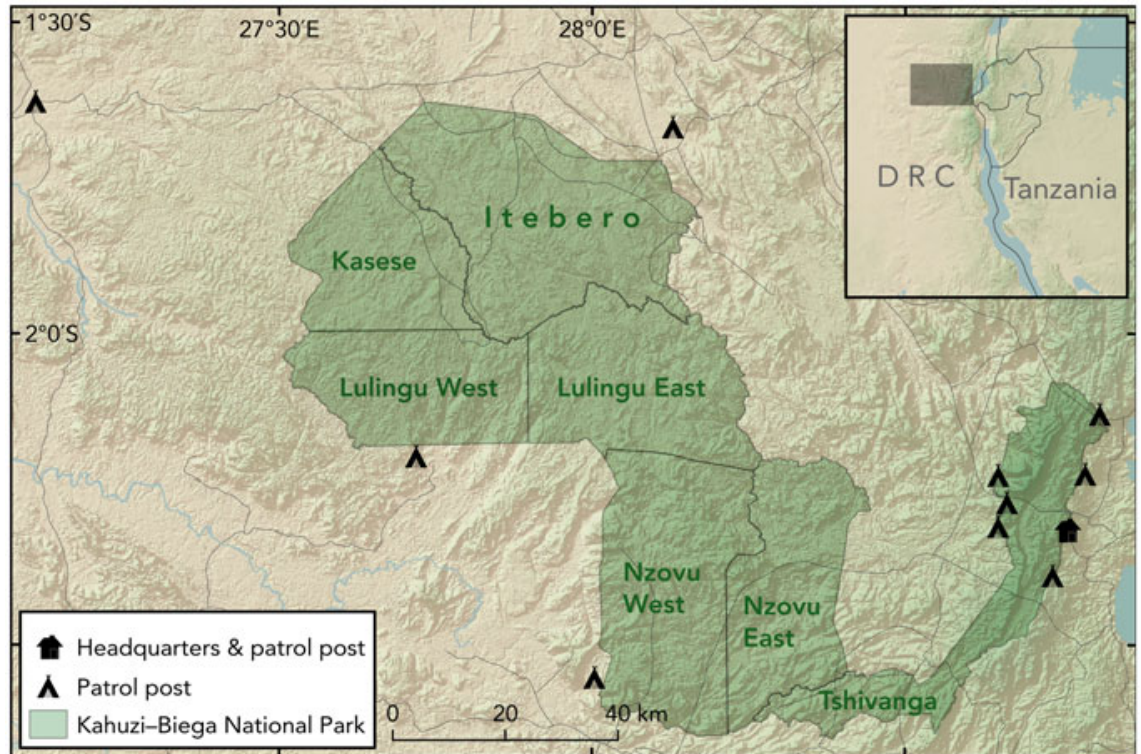

FIG. 1 Locations of ranger patrol posts and the Park headquarters in KahuziBiega National Park, Democratic Republic of the Congo.
Only a few studies have focused on wildlife rangers and even fewer have been conducted in African countries. Charles (1982) found that rangers working in Yellowstone National Park in the USA mostly chose this occupation because of their attachment to nature, the work itself and the desire to help people. Palmer \& Bryant (1985) and Eliason (2006) reported that most rangers in Virginia and Kentucky, respectively, found their job satisfying because they enjoyed the outdoors, their independence, the diversity and variety in their job, and meeting people. Moreto et al. (2016) found that most rangers working in Queen Elizabeth National Park, Uganda, enjoyed their job because of their perceived contribution to the country's conservation efforts, the financial stability and opportunities for personal and social development their work gave them, and the frontline work they conducted. In contrast, Ogunjinmi et al. (2008) found that most rangers working in the Yankari Game Reserve, Nigeria, were dissatisfied with their job and poorly motivated because of low salaries and the lack of incentive for performance. Moreto et al. (2017) reported that most rangers in Asia continued their work as rangers because they had no other job option. Although job satisfaction has been studied more in the policing sector than in the front-line conservation sector, it is likely that findings from research on police officers also apply to wildlife rangers, as both occupations are in law enforcement.

Rangers in the Democratic Republic of the Congo (DRC) are working to protect some of the largest remaining blocks of tropical rainforest, along with iconic species that are being targeted by poachers for the ivory trade, as trophies or pets, or for bushmeat (Hicks et al., 2010; Nelleman et al., 2010; Beyers et al., 2011; Kümpel et al., 2015; Spira et al., 2017). As a legacy of decades of civil war in the country there is an abundance of firearms, which continue to be used by armed groups and poachers. As a result, wildlife rangers are regularly confronted during their daily duties with wellarmed individuals (Reyntjens, 2009; Beyers et al., 2011). Since the 1990s, hundreds of rangers have been killed in the line of duty in eastern DRC (Marijnen, 2017). In light of the dangers and difficulties that the DRC rangers face, we examined what motivated those working in KahuziBiega National Park to choose this occupation, and what affects their job satisfaction, in an effort to help guide protected area managers in maintaining a motivated and effective ranger force (Moreto, 2016; Moreto et al., 2016). Understanding ways in which ranger motivation and effectiveness can be improved in such situations is key if conservation managers are to halt the decline in species in this park and in similar protected areas. Our study contributes to the scarce literature on wildlife rangers' occupational satisfaction, and we hope that it will encourage more conservation practitioners and protected area managers to assess and consider ways of improving ranger satisfaction and motivation at their sites.

\section{Study area}

Kahuzi-Biega National Park, a World Heritage Site in eastern DRC (Fig. 1), is one of the most important protected areas for the conservation of the endemic and Critically Endangered Grauer's gorilla Gorilla beringei graueri and many other species endemic to the Albertine Rift (Plumptre et al., 2007, 2016). The Park is managed by the Congolese wildlife authority (Institut Congolais pour la Conservation de la Nature, ICCN), which employed 86 rangers at the time of the study. All rangers were men, with a mean age of 44 years (range 25-67), and nearly all were 
married, with a mean of seven children (range 0-16). At the time of the study the Park had a functioning budget of c. USD 3 million, managed by the ICCN (Institut Congolais pour la Conservation de la Nature, 2015). The base ranger salaries paid by the Congolese government were USD 5060 per month, depending on rank, to which the ICCN added bonuses (USD 80-200 per month, depending on rank) funded by partner conservation organizations. At the time of the study the bonuses received by rangers were allocated by means of a subtractive system, by which the base bonus amount would be decreased by the number of work days a ranger had missed, and not according to how well the rangers had performed. Benefits included free but basic health care funded by the ICCN and partner conservation organizations, and simple accommodation at the Park headquarters unless rangers lived nearby, in which case they would commute to work daily.

\section{Methods}

Data were collected during December 2015-February 2016 through interviews conducted with ICCN rangers and heads of park programmes who were working in KahuziBiega National Park. Given the exploratory nature of our study, we used an ethnographic and socio-economic research approach based on a mixed methods design (Tashakkori \& Teddlie, 2010). A semi-structured questionnaire was administered to 62 of the 86 rangers $(72 \%$ of the Park's rangers) working in the Park at the time of the study, to collect quantitative data on their self-reported level of job satisfaction (high, medium or low) and both quantitative and qualitative data on why they chose to become rangers, what they liked and what they disliked about their job, and how they thought their motivation could be improved to conduct their work more effectively (open-ended questions). A separate semi-structured questionnaire consisting of open-ended questions intended to generate qualitative, contextual data on the rangers' work was administered to the seven heads of park programmes (chief warden and heads of administration, surveillance, boundary demarcation, wildlife/threat research and monitoring, tourism and community conservation) to assess their perception of the rangers' motivation and working conditions.

We identified a series of overarching themes from the qualitative data analysis, using descriptive coding to assign respondents' statements to categories (Saldaña, 2009) relating to aspects of (1) the rangers' work (namely salaries, benefits and promotions, core motivations and conservation aspirations), and (2) work environment (management of rangers, security and judicial support, and training and equipment). Within each theme we then compiled the various points discussed by respondents.
To assess which factors significantly affected the rangers' self-reported level of job satisfaction we collected additional data on their age, level of education (no formal education, primary, secondary), monthly salary range ( $<$ USD 150 , USD 150-250, > USD 250), years of service, living location (at the Park headquarters or not), additional household livelihood activities (yes/no), household well-being (see below), perceived likelihood of being promoted (yes/no), Park sectors they patrolled, type of patrols they conducted (surveillance, Park boundary demarcation, wildlife/threat research and monitoring, tourism) and mean duration of their patrols, all of which we hypothesized could be determinants of occupational satisfaction. Factors that significantly affected the rangers' self-reported level of satisfaction were identified using a cumulative link model, also known as a proportional odds model, which is suitable for the analysis of ordered categorical data (Christensen, 2015a). We included the interaction between age and years of service in the model, to account for a foreseeable correlation between these predictor variables. No assumption about the distance between adjacent ordered categories was made. A stepwise backwards selection process was used to select the minimal adequate model. Likelihood ratio tests (analyses of variance) were performed at each variable removal step to ensure that the simpler model did not lead to a statistically significant loss of fit. The rangers' household well-being was measured through the Basic Necessities Survey, which assigns an index of $0-1$ to a household, where 1 represents having all and o none of the items and services that a community considers to be its most basic necessities (Wilkie et al., 2015).

All interviews were conducted at the Park headquarters, where most of the survey respondents were located at the time of the study. Although rangers operate throughout Kahuzi-Biega National Park, they return to the headquarters for debriefing or for patrol rotations. We administered the surveys at a time when we knew that most of the Park staff would be present and available. We used a convenience sampling strategy to interview all the 62 rangers who were at the Park headquarters at that time. Fourteen rangers could not be interviewed because they were operating far from headquarters and did not return there regularly. A purposive sampling strategy was used to select the seven heads of programmes, who were surveyed to capture a wider range of perspectives relating to the rangers' work (Palinkas et al., 2015).

This study was approved and encouraged by the ICCN. Before starting an interview, surveyors explained to respondents that the survey was voluntary and the data would be kept confidential, how the data would be used and the goal of the study. Interviewees gave their informed consent to be part of the study and could interrupt the interviews whenever they wished. To minimize the potential for discomfort and unwillingness to provide honest answers, all surveys were conducted in private by surveyors who were familiar 
with the respondents through past and ongoing conservation work (Newing et al., 2011). Surveys with rangers were conducted in the local language, Swahili, and interviews with heads of programmes were conducted in French.

The data were analysed using $R$ 3.1.2 (R Development Core Team, 2014). For the cumulative link model we used the $R$ package ordinal with the default logit link (Christensen, 2015b). Statistical tests were considered significant at $\alpha=0.05$.

\section{Results}

Self-reported level of satisfaction, length of service and age

Most rangers reported they had a low level of job satisfaction $(53 \%, \mathrm{n}=33)$, some reported a medium level of satisfaction $(37 \%, \mathrm{n}=23)$ and only a minority said they were highly satisfied with their job $(10 \%, n=6)$.

The rangers surveyed had been working in Kahuzi-Biega National Park for a mean duration of 16 years (range 1-38) and those who had worked in the Park the longest were least satisfied with their job (Fig. 2a). Likewise, rangers who were the least satisfied with their jobs tended to be older (median 48 years old) than those with a medium or high level of satisfaction (median 43 and 42.5 years old, respectively; Fig. 2b). There was a positive correlation between length of service and age, as rangers with more years of experience were older (Spearman's correlation test: $r=0.75, \mathrm{P}<0.001$ ).

\section{Salaries, benefits and promotions}

Being able to earn a salary and receive benefits was the most commonly stated reason why rangers chose their profession ( $48 \%$, referred to as a 'means of survival' by respondents). However, the majority of rangers ( $72 \%$ of responses) and all seven heads of programmes indicated that the salary and bonuses were too low. The heads of programmes stated that this negatively affected the rangers' motivation in the field, making them less effective in protecting the Park. They also suggested that increased ranger revenue should come from increased base salaries rather than bonuses.

Lack of promotion was mentioned as something that rangers disliked about their job (50\% of responses). Although most of the rangers perceived that they could potentially be promoted during their career, $67 \%$ of those who believed they would not be promoted were dissatisfied with their job, compared to $41 \%$ among those who expected to be promoted in the future.

Mechanisms suggested by Park staff to improve the rangers' motivation included recognizing their work by providing medals (e.g. long-service medals), promotions or bonuses for rangers who work in higher risk zones or
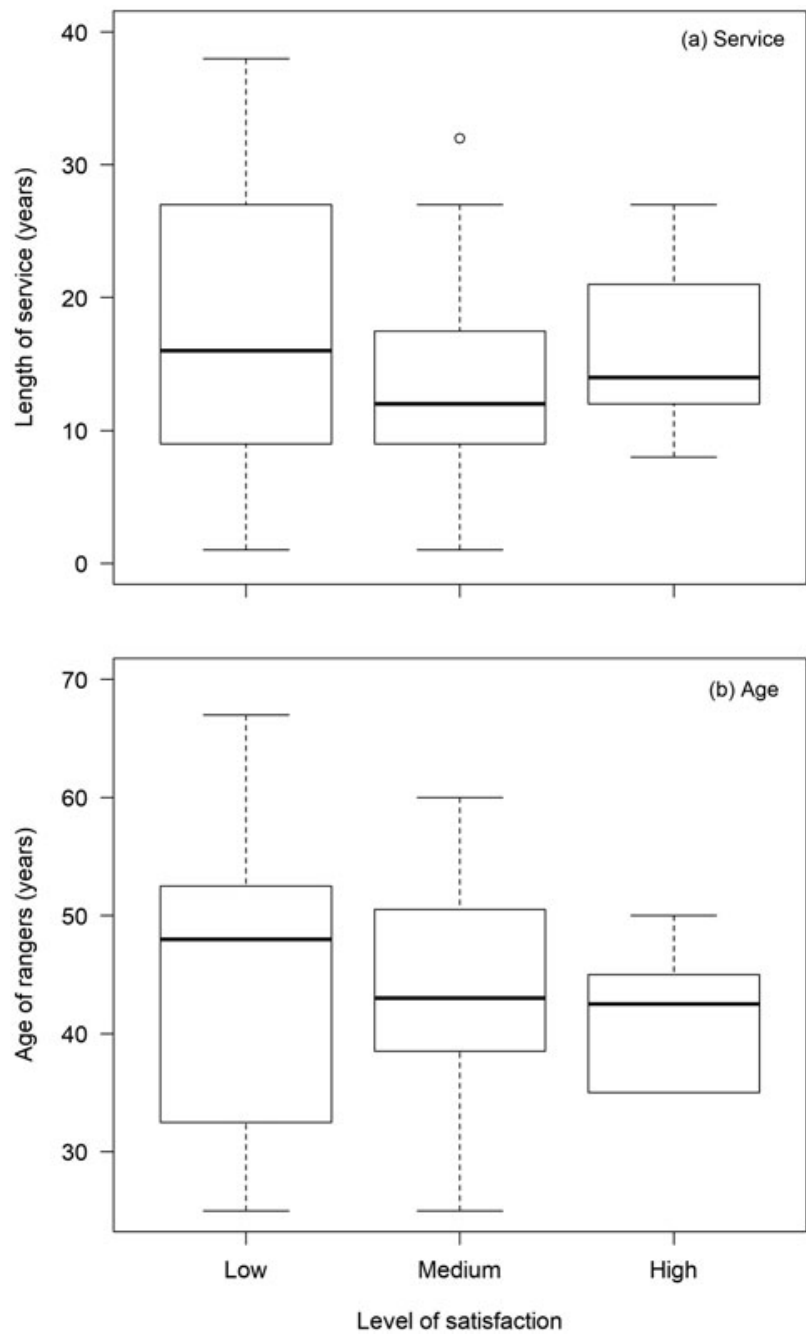

FIG. 2 Self-reported level of job satisfaction of rangers in Kahuzi-Biega National Park, DRC (Fig. 1) in the context of (a) length of service and (b) age of rangers. The box indicates the inter-quartile range, the dark horizontal line the median, the whiskers the minimum (bottom line) and maximum (top line), and the dot the outlier.

to reward actions of bravery or merit. Rangers stated that they would be more motivated if bonuses reflected their rank better, as this would encourage them to go beyond what is expected of them. Rangers also expressed the desire that benefits should include accommodation support for their families, as not all rangers are provided with free housing at the Park headquarters, and cover their children's school fees. Two heads of programmes specified that the rangers' motivation was negatively affected by the fact that ICCN does not guarantee a post-career pension.

\section{Core motivations and conservation aspirations}

A large proportion of respondents (44\%) said they chose to become rangers because they wanted to conserve nature, which provided inspiration for their work ( $7 \%$ of responses). Others responded that they became rangers to serve their 
country (3\%), because they considered the profession to be honourable $(3 \%)$, because it was their heritage (one ranger said he chose the profession because his father was a ranger) and because of the pride and esteem gained from working for the state ( $2 \%$ of responses). Some rangers stated that aspects of their job they liked included being in contact with nature (2\%), discovering places ( $2 \%)$ and managing ecosystems $(2 \%)$.

\section{Management of rangers}

Respondents identified a number of elements related to the management of the ranger workforce that contributed to their low motivation to do their work. These included having too few rangers for the size of the Park (86 rangers for $6,700 \mathrm{~km}^{2}$, or 1 ranger $/ 78 \mathrm{~km}^{2}$ ), a ranger workforce that is too old, and rangers who do not come from the towns and villages close to the Park, which reduced their ability to maintain good relationships with neighbouring communities. Being able to live with their family was an aspect of the job that rangers liked. Rangers that were transferred to sectors of the Park far from their home regarded it as punishment, because they were away from their families, the cost of living tended to be higher, and transfers were reported to be prolonged, irregular and sometimes for uncertain periods of time. A lack of road infrastructure and vehicle transportation meant that rangers often had to walk for several days before reaching their patrol posts. Shortening remote field placements was mentioned by four heads of programmes as a means to improve morale.

Rangers stated that they felt disregarded by some of the management staff and disrespected by other governmental services (mostly mentioning the Congolese army). Respondents also suggested that the ICCN's central office should provide army equivalent ranks to rangers so they would be recognized and respected by the army and other state law enforcement services.

\section{Security and judicial support}

Respondents stated that lack of security in the field was an aspect of their job that they disliked ( $2 \%$ of responses). One head of programme indicated that the difficulty of accessing certain parts of the Park, and the lack of security there make rangers scared and unmotivated to patrol these areas.

Rangers complained about being housed at basic patrol posts, sometimes lacking sanitary facilities, and located in remote and insecure locations where they felt they were at higher risk of attack by armed groups. Four heads of programmes suggested that renovating old patrol posts and building new ones would improve security for rangers and thus increase their motivation.
Three heads of programmes expressed concerns about the lack of judicial support and the repercussions that rangers may face as a result of performing their duty, as they can be sentenced to time in prison if they kill an individual in self-defence or by accident during a patrol. This makes their job more risky, as they are often confronted with wellarmed individuals (poachers, militias) against whom they have to defend themselves. Two rangers lost their lives in the Park and many more were injured in such incidents during 2015-2018. Respondents stated that offenders transferred to local courts are often freed after a short period of time, and the rangers involved in their arrest feared retaliation. Likewise, rangers can be reluctant to arrest members of their own community because of the risk of being ostracized. Overall, rangers did not feel that the state or Park authority supported them sufficiently regarding these issues, which made them reluctant to make arrests or take action during patrols, and this reduced their effectiveness in the field.

\section{Training and equipment}

Respondents stated that they liked receiving training, equipment and food rations for patrols, although they indicated that more support was needed. All heads of programmes stated more training and better equipment were needed, especially in relation to weapons and ammunition, and replacement of old equipment such as uniforms and raincoats, which deteriorate quickly. Two heads of programmes added that the uniform is a source of pride among rangers: it inspires respect, reflects the ICCN's image and is good for the rangers' morale. One head of programme specified that the government should provide equipment for rangers as it does for the army, which could also help to reduce the army's disregard for rangers.

\section{Model results}

The cumulative link model indicated that a ranger's role (i.e. the type of patrol he conducts) was one of the strongest predictors of job satisfaction (Table 1). Conducting Park boundary demarcation patrols had a positive effect on ranger satisfaction, whereas conducting wildlife/threat research and monitoring patrols had a negative effect. The Park sector patrolled was also a statistically significant predictor of job satisfaction, with patrol assignments in the Kasese sector (the furthest from the Park headquarters, where rangers have to walk for 5 days to reach their patrol post from the nearest airstrip) having a negative effect on job satisfaction.

Living at the Park headquarters (i.e. receiving free housing) was a positive factor in the rangers' level of satisfaction. The interaction between age and length of service was a negative predictor of job satisfaction, meaning that the more years a ranger works at the Park and the older he 
TABLE 1 Results of the cumulative link model applied to the self-reported level of job satisfaction among rangers in Kahuzi-Biega National Park, DRC (Fig. 1). The threshold coefficient estimates are cut-off points that differentiate the response variable levels (low, medium, high).

\begin{tabular}{|c|c|c|c|c|}
\hline & Estimate & SE & $z$ & $\mathrm{P}$ \\
\hline \multicolumn{5}{|l|}{ Variable parameters } \\
\hline Park boundary demarcation patrols & 2.756 & 1.004 & 2.746 & 0.006 \\
\hline Living at the headquarters & 2.067 & 0.786 & 2.630 & 0.009 \\
\hline Years of service & 0.707 & 0.282 & 2.505 & 0.012 \\
\hline Age & 0.184 & 0.069 & 2.668 & 0.008 \\
\hline Years of service $\times$ Age & -0.016 & 0.006 & -2.771 & 0.006 \\
\hline Wildlife/threat research \& monitoring patrols & -2.146 & 1.019 & -2.105 & 0.035 \\
\hline Patrols in Kasese sector & -2.311 & 1.023 & -2.260 & 0.024 \\
\hline \multicolumn{5}{|l|}{ Threshold parameters } \\
\hline Low to medium & 7.492 & 2.897 & 2.586 & \\
\hline Medium to high & 10.553 & 3.116 & 3.387 & \\
\hline
\end{tabular}

gets, the less satisfied with his job he is likely to become. Because the interaction between these variables was a significant predictor of job satisfaction, it was not relevant to take their individual effects into account (Aiken et al., 1991). Level of education, salary range, additional household livelihood activities, household well-being, perceived likelihood of being promoted, and mean patrol duration did not have statistically significant effects in the model.

\section{Discussion}

\section{Factors of job satisfaction and motivation}

We found that most rangers working in Kahuzi-Biega National Park were dissatisfied with their job and with various aspects of their work environment. These findings are similar to those of Ogunjinmi et al. (2008) in the Yankari Game Reserve, Nigeria, where the majority of rangers were dissatisfied with their job, and contrast with those of Moreto et al. (2016) from Queen Elizabeth National Park, Uganda, where rangers enjoyed their job.

Although rangers gave a wide range of reasons for their low occupational satisfaction and motivation, our model revealed that the most significant predictors of poor job satisfaction were being older and working at the Park longer, not receiving free housing at the Park headquarters, being posted in remote locations and conducting patrols in high-risk areas.

The negative influence of long service and age on job satisfaction is consistent with results from Miller et al. (2009) for U.S. police officers, but not with those of Ogunjinmi et al. (2008), who found that the number of years of experience was positively correlated with job satisfaction among rangers in Nigeria. The fact that respondents in KahuziBiega National Park recognized that having a younger ranger workforce would improve overall motivation and effectiveness further supports these findings. Rangers who have worked the longest may not feel their expectations have been fulfilled, which leads them to become unmotivated and dissatisfied with their job (White et al., 2010; Johnson, 2012).

Receiving free housing benefits significantly improved ranger satisfaction, probably because of the multitude of advantages it offers. In particular, rangers can work closer to their families, and have reduced living costs, easy access to services, including water, health care, and schooling for their children, and an increased sense of security. As only a limited number of rangers can receive free housing at the Park headquarters, those who do not receive this benefit may feel unhappy about this inequality.

The type and remoteness of patrols were the strongest predictors of job satisfaction. Intuitively, this may be because patrols make up most of the tasks that rangers have to perform and are therefore the strongest determinant of their occupational satisfaction. The fact that Park boundary demarcation patrols affected job satisfaction positively whereas wildlife/threat research and monitoring patrols had a negative effect may be a consequence of operational differences. Boundary demarcation patrols are conducted along the Park boundary and are not as remote as wildlife/threat research and monitoring patrols, which are often conducted further inside the Park, away from its boundaries, and tend to last several weeks at a time. Patrols conducted in less isolated areas may also be safer. Kahuzi-Biega National Park, like much of eastern DRC, has a high presence and level of activity of armed militias, which continue to create insecurity and make rangers unwilling and even unable to patrol in some areas of the Park (Stearns et al., 2013). Rangers are less numerous and often poorly armed in comparison with the Congolese army, and are therefore vulnerable to attack.

Although salary was not a statistically significant predictor of job satisfaction in our model, it was mentioned frequently during interviews, by both rangers and heads of programmes. Low salaries have been found to be associated with poor job motivation and satisfaction in law enforcement jobs, especially considering the hazards and risks 
involved (Toch, 2002; Claridge et al., 2005; Ogunjinmi et al., 2008; Kakira, 2010; Eliason, 2011; Moreto, 2016). Ranger salaries at Kahuzi-Biega National Park were USD 130-26o per month (depending on rank), which is higher than the USD 50-168 paid monthly to rangers in Nigeria (Ogunjinmi et al., 2008) but lower than the mean of USD 200 received per month by rangers in Uganda (Moreto et al., 2015). Poorly paid individuals may be more susceptible to corruption, as found in Queen Elizabeth National Park and in KahuziBiega National Park, where some rangers admitted that their low salaries drove them to help community members conduct illegal activities in the Park in exchange for bribes (Kakira, 2010; Moreto et al., 2015).

The lack of judicial support affected the rangers' motivation. This challenge is not unique to the DRC and has been noted as one of the major issues facing contemporary conservation law enforcement officers (Eliason, 2011; Moreto, 2016). Rangers in Kahuzi-Biega National Park felt unsafe and uncommitted to conducting their job effectively because of the risk of being detained themselves or becoming the victim of revenge by their community or those they arrested. These risks could potentially incite rangers to accept bribes from offenders rather than to arrest them.

\section{Implications for conservation, and recommendations}

Ensuring rangers are satisfied with their job is one of the key conditions that needs to be fulfilled to have an effective law enforcement workforce and therefore a positive conservation impact (Henson et al., 2016). Our study and others (e.g. Miller et al., 2009) have identified the need for a reasonably young workforce, to prevent decreasing morale. After this study, and noting this issue, the ICCN recruited 110 new rangers for Kahuzi-Biega National Park in 2016, including the Park's first four female rangers, thus increasing the density of rangers operating in the Park to 1 ranger $/ 34 \mathrm{~km}^{2}$. The new recruits were all 20-35 years old, reducing the mean age of rangers from 44 to 34 years. An effort was made to select rangers from communities around the Park, to limit the number of rangers posted far from their families.

Being allocated to work in more remote and therefore high-risk locations for uncertain periods of time was something that rangers disliked about their occupation. A 2015 study revealed that most illegal artisanal mine sites located within the Park were controlled by, and sustained, armed groups, and fuelled bushmeat hunting and other illegal activities (Spira et al., 2017). Occasionally joint patrols are conducted by the ICCN and the army, but Congolese army missions to remove armed groups from the Park have sometimes resulted in retaliations against rangers, who are perceived as allies of the army. A similar situation occurred during the civil unrest in Rwanda in 1997-1998, when numerous members of staff from Nyungwe and Volcanoes National Parks were killed by armed groups because they were accompanying the Rwandan army to patrol in dangerous areas, and were therefore targeted as allies of the new government (Plumptre, 2003). As rangers are not equipped or mandated to be the nation's peacekeeping force, the solution is for the Congolese army to demilitarize the country's national parks so that rangers can enforce conservation laws (Spira et al., 2017). In addition the DRC judicial system needs to be improved to make sure that offenders serve their sentences, and are punished if they retaliate against rangers in revenge for having been arrested (Henson et al., 2016). Furthermore, without specific legal measures to prevent rangers from being sentenced to prison if they injure or kill someone in self-defence, rangers will continue to avoid confrontation with offenders, which defeats their professional purpose. Although providing rangers with free housing as a benefit was a positive factor of job satisfaction, we do not recommend it in the long term, as beneficiary rangers could find it difficult to give up this benefit after many years of service.

Moreto et al. (2016) found that in situations where rangers were highly satisfied with their job they 'recognized the importance of protected areas and wildlife in the economic development of the country, and felt that they personally contributed to national advancement'. Therefore, in situations in which there is no funding to increase ranger salaries we encourage park managers to use alternative ways of motivating rangers, such as through strong leadership, by recognizing their performance, or by positively reinforcing their motivation based on knowledge of the core motivations that made them choose this profession (Jachmann, 2008; Henson et al., 2016).

In Kahuzi-Biega National Park receiving recognition and respect from management staff, the army and government authorities, and receiving training, promotions and incentives for high performance would probably lead to higher job motivation, satisfaction, performance, commitment and tenure, as found in other studies (Near, 1985; Burke, 1989; Ogunjinmi et al., 2008). The use of law enforcement monitoring tools such as the Spatial Monitoring and Reporting Tool (SMART) to measure ranger performance has the potential to motivate rangers by empowering them, giving them responsibilities and involving them in park management (Gray \& Kalpers, 2005; Stokes, 2010), but should not be used as a tool for micro-management of rangers. Since 2014 rangers in Kahuzi-Biega National Park have been using SMART, which documents ranger performance and achievements and could be used as a basis for establishing positive performance-based awards (Cameron et al., 2001); however, this has yet to be put in place. For example, protected area managers could reward rangers on an annual basis, using SMART to identify rangers who have patrolled the longest distances or removed the most snares over the previous year. This could create a spirit of competition among rangers and thus increase their 
motivation and performance (Jachmann, 2008). This type of incentive led to a $59 \%$ increase in patrol performance, on average, when it was applied in protected areas in Ghana (Jachmann, 2008).

Our findings highlight numerous ways in which ranger satisfaction could be improved, mostly related to their work environment. These include higher salaries, more promotion opportunities, recognition from the Congolese government, positive performance incentives, better security, improved living conditions in remote patrol posts and more support from the judicial system. Increasing rangers' job satisfaction could lead to a higher commitment to the profession and therefore to improved performance, which could in turn result in positive outcomes for wildlife conservation (Judge et al., 2001; White et al., 2010). When conducting ecological research in protected areas, researchers should consider ways of improving ranger satisfaction and ensure the rangers' needs are adequately taken into account.

Acknowledgements We thank the U.S. Agency for International Development for supporting this study, Alain Twendilonge, Blandine Bishengezi, Fidèle Kavuba (Wildlife Conservation Society), Patricia Kimengele for conducting the interviews, Samantha Strindberg (Wildlife Conservation Society) for help with interpreting the model, Deo Kujirakwinja (Wildlife Conservation Society) and the anonymous reviewers for their insightful and constructive comments, the staff of Kahuzi-Biega National Park, in particular Radar Nishuli, who was the Park Director at the time of the study, and the rangers who took part in the survey and provided invaluable information about their work.

Author contributions Survey design and administration, training of data collectors, data analysis and writing: CS; survey design and administration, data collection and writing: AK; survey design and writing: AJP.

\section{Conflicts of interest None.}

Ethical standards This research followed the guidelines of the British Sociological Association, fully involved Congolese researchers and the Congolese wildlife authority (ICCN), and was approved and encouraged by the ICCN.

\section{References}

Aiken, L.S., West, S.G. \& Reno, R.R. (1991) Multiple Regression: Testing and Interpreting Interactions. SAGE Publications, Thousand Oaks, USA.

Beyers, R.L., Hart, J.A., Sinclair, A.R.E., Grossmann, F., Klinkenberg, B. \& Dino, S. (2011) Resource wars and conflict ivory: the impact of civil conflict on elephants in the Democratic Republic of Congo - the case of the Okapi Reserve. PLOS ONE, 6, e27129.

Biggs, D., Cooney, R., Roe, D., Dublin, H., Allan, J., Challender, D. \& Skinner, D. (2015) Engaging Local Communities in Tackling Illegal Wildlife Trade: Can a 'Theory of Change' Help? IIED Discussion Paper. IIED, London, UK.

Brough, P. \& Frame, R. (2004) Predicting police job satisfaction and turnover intentions: the role of social support and police organisational variables. New Zealand Journal of Psychology, 33, 8-16.
BURKE, R.J. (1989) Examining the career plateau: some preliminary findings. Psychological Reports, 65, 295-306.

Butchart, S.H.M., Walpole, M., Collen, B., van Strien, A., Scharlemann, J.P.W, Almond, R.E.A. et al. (2010) Global biodiversity: indicators of recent declines. Science, 328, 1164-1168.

Cameron, J., Banko, K.M. \& Pierce, W.D. (2001) Pervasive negative effects of rewards on intrinsic motivation: the myth continues. The Behavior Analyst, 24, 1-44.

Charles, M.T. (1982) The Yellowstone ranger: the social control and socialization of federal law enforcement officers. Human Organization, 41, 216-226.

Christensen, R.H.B. (2015a) Analysis of Ordinal Data with Cumulative Link Models-Estimation with the Ordinal Package. Https://docplayer.net/17933339-Analysis-of-ordinal-data-withcumulative-link-models-estimation-with-the-r-package-ordinal. html [accessed 15 June 2016].

Christensen, R.H.B. (2015b) ordinal: Regression Models for Ordinal Data. Http://www.cran.r-project.org/package=ordinal/ [accessed 15 June 2016].

Claridge, G., Chea-Leth, V. \& Van Chhoan, I. (2005) The Effectiveness of Law Enforcement Against Forest and Wildlife Crime: A Study of Enforcement Disincentives and Other Relevant Factors in Southwestern Cambodia. East-West Management Institute, Conservation International, and U.S. Agency for International Development, Washington, DC, USA.

Eliason, S.L. (2006) Factors influencing job satisfaction among state conservation officers. Policing: An International Journal of Police Strategies \& Management, 29, 6-18.

Eliason, S.L. (2011) Policing natural resources: issues in a conservation law enforcement agency. Professional Issues in Criminal Justice, 6, 43-58.

Gray, M. \& Kalpers, J. (2005) Ranger based monitoring in the Virunga-Bwindi region of East-Central Africa: a simple data collection tool for park management. Biodiversity and Conservation, 14, 2723-2741.

Henson, D.W., Malpas, R.C. \& D’Udine, F.A.C. (2016) Wildlife Law Enforcement in Sub-Saharan African Protected Areas: a Review of Best Practices. Occasional Paper of the IUCN Species Survival Commission. IUCN, Gland, Switzerland.

Hicks, T.C., Darby, L., Hart, J., Swinkels, J., January, N. \& Menken, S. (2010) Trade in orphans and bushmeat threatens one of the Democratic Republic of the Congo's most important populations of Eastern chimpanzees (Pan troglodytes schweinfurthii). African Primates, 29, 566-570.

Hilborn, R., Arcese, P., Borner, M., Hando, J., Hopcraft, G., Lоiвоокі, M. et al. (2006) Effective enforcement in a conservation area. Science, 314, 1266.

Hoath, D.R., Schneider, F.W. \& Starr, M.W. (1998) Police job satisfaction as a function of career orientation and position tenure: implications for selection and community policing. Journal of Criminal Justice, 26, 337-347.

Hötte, M.H.H., Kolodin, I.A., Bereznuk, S.L., Slaght, J.C., KerLey, L.L., SOUt y RINA, S.V. et al. (2016) Indicators of success for smart law enforcement in protected areas: a case study for Russian Amur tiger (Panthera tigris altaica) reserves. Integrative Zoology, 11, 2-15.

Institut Congolais pour la Conservation de la Nature (2015) Plan Opérationnel de 2015 du Parc National de Kahuzi-Biega. Kahuzi-Biega National Park, Democratic Republic of Congo.

Jachmann, H. (2008) Monitoring law-enforcement performance in nine protected areas in Ghana. Biological Conservation, 141, 89-99.

Johnson, R.R. (2012) Police officer job satisfaction: a multidimensional analysis. Police Quarterly, 15, 157-176. 
Judge, T.A., Thoresen, C.J., Bono, J.E. \& Patton, G.K. (2001) The job satisfaction-job performance relationship: a qualitative and quantitative review. Psychological Bulletin, 127, 376-407.

KAKIRA, L.M. (2010) Monitoring law enforcement effort and illegal activity in selected protected areas: implications for management and conservation, Democratic Republic of Congo. MSc thesis. University of Ghent, Ghent, Belgium.

Kúmpel, N.F., Quinn, A. \& Grange, S. (2015) The distribution and population status of the elusive okapi, Okapia johnstoni. African Journal of Ecology, 53, 242-245.

Lambert, E.G., Qureshi, H., Hogan, N.L., Klahm, C., Smith, B. \& Frank, J. (2015) The association of job variables with job involvement, job satisfaction, and organizational commitment among Indian police officers. International Criminal Justice Review, $25,194-213$.

LAWson, K. \& Vines, A. (2014) Global Impacts of the Illegal Wildlife Trade: The Costs of Crime, Insecurity and Institutional Erosion. Chatham House, London, UK.

Leader-Williams, N., Albon, S.D. \& Berry, P.S.M. (1990) Illegal exploitation of black rhinoceros and elephant populations: patterns of decline, law enforcement and patrol effort in Luangwa Valley, Zambia. Journal of Applied Ecology, 27, 1055-1087.

Marijnen, E. (2017) The 'green militarisation' of development aid: the European Commission and the Virunga National Park, DR Congo. Third World Quarterly, 38, 1566-1582.

Miller, H.A., Mire, S. \& Kim, B. (2009) Predictors of job satisfaction among police officers: does personality matter? Journal of Criminal Justice, 37, 419-426.

Moreto, W.D. (2016) Occupational stress among law enforcement rangers: insights from Uganda. Oryx, 50, 646-654.

Moreto, W.D., Brunson, R.K. \& Braga, A.A. (2015) 'Such misconducts don't make a good ranger': examining law enforcement ranger wrongdoing in Uganda. The British Journal of Criminology, $55,359-380$.

Moreto, W.D., Lemieux, A.M. \& Nobles, M.R. (2016) 'It's in my blood now': the satisfaction of rangers working in Queen Elizabeth National Park, Uganda. Oryx, 50, 655-663.

Moreto, W.D., Gau, J.M., Paoline, E.A., Singh, R., Belecky, M. \& LoNG, B. (2017) Occupational motivation and intergenerational linkages of rangers in Asia. Oryx, published online 22 August 2017.

NEAR, J.P. (1985) A discriminant analysis of plateaued versus nonplateaued managers. Journal of Vocational Behavior, 26, 177-188.

Nelleman, C., Redmond, I. \& Refisch, J. (eds) (2010) The Last Stand of the Gorilla: Environmental Crime and Conflict in the Congo Basin. A Rapid Response Assessment. United Nations Environment Programme, GRID-Arendal.

Newing, H., Eagle, C., Puri, R. \& Watson, C.W. (2011) Conducting Research in Conservation: A Social Science Perspective. Routledge, Abingdon, UK.

O'Leary-Kelly, A.M. \& Griffin, R.W. (2013) Job satisfaction and organizational commitment. Psychology and Policing (eds N. Brewer \& C. Wilson), pp. 367-394. Psychology Press, London, UK.

Ogunjinmi, A.A., Umunna, M.O. \& Oguninmi, K.O. (2008) Factors affecting job satisfaction of rangers in Yankari Game Reserve, Bauchi, Nigeria. Journal of Agriculture and Social Research, 8, 1-9.

Palinkas, L.A., Horwitz, S.M., Green, C.A., Wisdom, J.P., Duan, N. \& Hoagwood, K. (2015) Purposeful sampling for qualitative data collection and analysis in mixed method implementation research. Administration and Policy in Mental Health and Mental Health Services Research, 42, 533-544.

Palmer, C.E. \& Bryant, C.D. (1985) Keepers of the king's deer. Game wardens and the enforcement of fish and wildlife law. In The Rural Workforce: Non-agricultural Occupations in America (eds C.D. Bryant, D.J. Shoemaker, J.K. Skipper \& W.E. Snizek), pp. 111-137. Bergin \& Garvey, Westport, USA.

Plumptre, A.J. (2003) Lessons learned from on-the-ground conservation in Rwanda and the Democratic Republic of the Congo. Journal of Sustainable Forestry, 16, 69-88.

Plumptre, A.J., Davenport, T.R.B., Behangana, M., Kityo, R., Eilu, G., Ssegawa, P. et al. (2007) The biodiversity of the Albertine Rift. Biological Conservation, 134, 178-194.

Plumptre, A.J., Nixon, S., Kujirakwinja, D.K., Vieilledent, G., Critchlow, R., Williamson, E.A. et al. (2016) Catastrophic decline of world's largest primate: $80 \%$ loss of Grauer's gorilla (Gorilla beringei graueri) population justifies Critically Endangered status. PLOS ONE, 11, e0162697.

R Development Core Team (2014) R: A Language and Environment for Statistical Computing. R Foundation for Statistical Computing, Vienna, Austria. Http://www.r-project.org/ [accessed 17 December 2018].

Reyntjens, F. (2009) The Great African War: Congo and Regional Geopolitics, 1996-2006. Cambridge University Press, Cambridge, UK

Rothmann, S. (2008) Job satisfaction, occupational stress, burnout and work engagement as components of work-related wellbeing. South Africa Journal of Industrial Psychology, 34, 11-16.

Saldaña, J. (2009) The Coding Manual for Qualitative Researchers. Sage Publications, Thousand Oaks, USA.

Spira, C., Kirkby, A., Kujirakwinja, D. \& Plumptre, A.J. (2017) The socio-economics of artisanal mining and bushmeat hunting around protected areas: Kahuzi-Biega National Park and Itombwe Nature Reserve, eastern Democratic Republic of Congo. Oryx, published online 11 April 2017.

Stearns, J. et al. (2013) Raia Mutomboki: The Flawed Peace Process in the DRC and the Birth of an Armed Franchise. The Rift Valley Institute, London, UK.

StOKes, E.J. (2010) Improving effectiveness of protection efforts in tiger source sites: developing a framework for law enforcement monitoring using MIST. Integrative Zoology, 5, 363-377.

Tashakkori, A. \& Teddlie, C. (eds) (2010) Handbook of Mixed Methods in Social \& Behavioral Research. Sage Publications, Thousand Oaks, USA.

The World BAnk (2016) Analysis of International Funding to Tackle Illegal Wildlife Trade. World Bank, Washington, DC, USA.

Toch, H. (2002) Stress in Policing. American Psychological Association, Washington, DC, USA

White, M.D., Cooper, J.A., SAunders, J. \& Raganella, A.J. (2010) Motivations for becoming a police officer: re-assessing officer attitudes and job satisfaction after six years on the street. Journal of Criminal Justice, 38, 520-530.

Wilkie, D., Wieland, M. \& Detoeuf, D. (2015) A Guide to the Modified Basic Necessities Survey: Why and How to Conduct BNS in Conservation Landscapes. WCS, New York, USA.

Zhao, J., Thurman, Q. \& He, N. (1999) Sources of job satisfaction among police officers: a test of demographic and work environment models. Justice Quarterly, 16, 153-173. 